\title{
Características de Carcaça e da Carne de Novilhos Hereford Terminados em Confinamento com Diferentes Fontes de Volumoso
}

\author{
Fabiano Nunes Vaz'1, João Restle ${ }^{2}$
}

\begin{abstract}
RESUMO - Objetivou-se, com este trabalho, estudar as características de carcaça e da carne de novilhos Hereford terminados em confinamento por 112 dias e alimentados com dietas isoprotéicas (12\% de proteína bruta) contendo, na matéria seca, $33 \%$ de concentrado e $67 \%$ de cana-de-açúcar ou silagem de milho. Foram utilizados doze novilhos, com idade de 20 meses. O peso de fazenda, peso de carcaça quente e peso de carcaça fria foram maiores nos novilhos alimentados com silagem de milho, sendo, respectivamente, 446,230 e $227 \mathrm{~kg}$ contra 421, 211 e $208 \mathrm{~kg}$, citados na mesma ordem, para os novilhos alimentados com cana-de-açúcar. Não houve diferença entre tratamentos para rendimento de carcaça fria, quebra durante o resfriamento e porcentagem dos cortes comerciais da carcaça. $\mathrm{O}$ comprimento de carcaça foi maior nos novilhos alimentados com silagem de milho (125 vs $122 \mathrm{~cm}$ ), mas a fonte de volumoso não afetou a conformação de carcaça, espessura de gordura de cobertura, área de Longissimus dorsi, assim como as porcentagens de músculo e osso na carcaça, sendo que, na média dos dois tratamentos, essas características apresentaram valores de 9,5 pontos, 5,04 mm, $58,1 \mathrm{~cm}^{2}, 63,7$ e $15,4 \%$. Novilhos alimentados com silagem de milho apresentaram maior porcentagem de gordura na carcaça (23,2 vs $20,6 \%$ ). Não houve diferença significativa nas características cor, textura, marmoreio, força de cizalhamento, maciez e quebra na cocção da carne, mas a quebra ao descongelamento foi maior nos animais alimentados com cana-de-açúcar (6,10 vs 3,69\%).
\end{abstract}

Palavras-chave: cana-de-açúcar, qualidade da forragem, qualidade da carne, rendimento de carcaça, silagem de milho

\section{Carcass and Meat Characteristics of Hereford Steers Finished in Feedlot with Different Roughage Sources}

\begin{abstract}
The objective of this work was to study the carcass and meat characteristics of Hereford steers, finished in feedlot for 112 days and fed with $33 \%$ concentrate and $67 \%$ chopped sugar cane or corn silage diets, containing $12 \%$ of crude protein. Twelve steers, with 20 months of age, were used. Slaughter weight, hot carcass weight and cold carcass weight were higher for steers fed corn silage, being, respectively, 446, 230 and $227 \mathrm{~kg}$ vs 421, 211 and $208 \mathrm{~kg}$, in the same order, for animals fed chopped sugar cane. No significant differences among treatments were observed for cold dressing percentage, chilling loss and commercial cuts percentage. Carcass length was higher for steers fed corn silage (125 vs $122 \mathrm{~cm}$ ), but the roughage source did not affect the carcass conformation, fat thickness, longissimus dorsi area, as well as carcass muscle and bone percentages, being the averages of the two treatments, for these this characteristics, respectively, 9.5 points, $5.04 \mathrm{~mm}, 58.1 \mathrm{~cm}^{2}, 63.7$ and $15.4 \%$. Steers fed corn silage showed higher fat percentage (23.2 vs $20.6 \%$ ). No significant difference were observed for meat color, texture, marbling, Shear value, tenderness and cooking loss, but the thawing loss was higher for steers fed chopped sugar cane (6.10 vs $3.69 \%)$.
\end{abstract}

Key Words: corn silage, dressing percentage, forage quality, meat quality, chopped sugar cane

\section{Introdução}

Nos últimos anos, a pecuária de corte brasileira apresentou um bom ganho de produtividade, à medida que começaram a ser utilizados alimentos concentrados e de maior valor nutritivo para animais de raças precoces, mas com bom potencial de crescimento, como é o caso da raça Hereford (Sherbeck et al., 1995; Restle et al., 1999, Vaz \& Restle, 2000). No entanto, embora os alimentos concentrados desempenhem papel fundamental para reduzir a idade de abate dos novilhos e, consequentemente, melhorar a qualidade da carne bovina (Vaz \& Restle, 1998) visando atender consumidores cada vez mais exigentes (Restle \& Vaz, 2002), ainda é a fração volumosa a que participa em maior proporção na dieta dos animais.

Durante vários anos, a cana-de-açúcar foi amplamente utilizada para bovinos confinados, sendo que a mesma começou a ser substituída por alimentos volumosos de maior concentração energética, à medida que se procurava melhor desempenho dos animais (Brondani \& Restle, 1991; Restle et al., 1996).

\footnotetext{
${ }^{1}$ Zootecnista, Bolsista do CNPq, Aluno do curso de Doutorado CEPAN - UFRGS. Rua Benjamin Constant, 930/313, Santa Maria - RS CEP: 97050-020 (fnvaz@terra.com.br).

${ }^{2}$ Eng. Agr., Professor Visitante CNPq - Departamento de Produção Animal - EV/UFG, Campus Samambaia, C.P. 131 - Goiânia - GO
} (jorestle@terra.com.br). 
Os alimentos oferecidos durante a terminação têm efeito significativo nas diferenças observadas no rendimento de carcaça em bovinos, devido às diferenças que ocorrem no desenvolvimento do trato digestório. O rendimento diminui em animais que necessitam maior consumo de alimentos para suprir as exigências fisiológicas ou são submetidos a dietas compostas com alimentos de baixa velocidade de passagem pelo trato digestório (Di Marco, 1998). Nesses casos ocorre maior desenvolvimento do rúmen-retículo, resultando em animais com maior peso do trato digestório cheio e vazio, assim como maior quantidade de couro para envolver maior arqueamento de costelas (Vaz et al., 2001).

Objetivou-se, com este trabalho, estudar o efeito do uso de silagem de milho ou cana-de-açúcar na terminação em confinamento de novilhos de raças precoces, como a Hereford, sobre as características quantitativas e qualitativas da carcaça e da carne, bem como estabelecer as correlações entre essas variáveis.

\section{Material e Métodos}

Otrabalho foi conduzido no Setor de Bovinocultura de Corte do Departamento de Zootecnia da Universidade Federal de Santa Maria, situada na Depressão Central do Rio Grande do Sul.

Doze novilhos da raça Hereford, com idade de 20 meses, contemporâneos, oriundos do mesmo rebanho e mantidos sempre sob as mesmas condições de manejo, alimentação e sanidade, foram aleatoriamente divididos em dois tratamentos, conforme a fonte de volumoso (silagem de milho ou cana-de-açúcar) fornecida durante a terminação. A fase experimental em confinamento (112 dias) foi dividida em quatro períodos de 28 dias cada. Consta na Tabela 1 a composição das dietas nos diferentes períodos.

O nível de concentrado variou nos diferentes períodos experimentais, mas a fórmula do concentrado foi a mesma para os dois tratamentos, sendo que os animais que consumiram cana-de-açúcar receberam uréia misturada diretamente no cocho no momento do fornecimento, visando manter a dieta dos dois tratamentos com $12 \%$ de proteína bruta (Tabela 1).

$\mathrm{O}$ abate ocorreu quando os animais atingiram, na média, aproximadamente $5 \mathrm{~mm}$ de gordura de cobertura, quando todos foram comercializados (na mesma data). Antes do embarque para o frigorífico, os animais foram submetidos a um jejum de sólidos de 12 horas, sendo posteriormente pesados, obtendo-se, dessa maneira, o peso de fazenda dos animais.

R. Bras. Zootec., v.34, n.1, p.230-238, 2005
Tabela 1 - Composição percentual das dietas de acordo com o período experimental

Table 1 - Diet composition according to the experimental period

\begin{tabular}{|c|c|c|c|c|}
\hline \multirow[t]{2}{*}{$\begin{array}{l}\text { Ingrediente, } \% \\
\text { Ingredient, } \%\end{array}$} & \multicolumn{4}{|c|}{$\begin{array}{l}\text { Período experimental } \\
\text { Experimental period }\end{array}$} \\
\hline & 1 & 2 & 3 & 4 \\
\hline Concentrado & 22,000 & 24,000 & 39,000 & 44,000 \\
\hline Concentrate & & & & \\
\hline $\begin{array}{l}\text { Farelo de arroz } \\
\text { Rice bran }\end{array}$ & 5,729 & 7,030 & 11,575 & 13,424 \\
\hline $\begin{array}{l}\text { Grão de milho } \\
\text { Corn grain }\end{array}$ & 1,692 & 2,578 & 13,268 & 16,540 \\
\hline $\begin{array}{l}\text { Farelo de soja } \\
\text { Soybean meal }\end{array}$ & 13,246 & 12,948 & 11,856 & 11,449 \\
\hline $\begin{array}{l}\text { Farinha de ossos } \\
\text { Bone meal }\end{array}$ & 0,458 & 0,499 & 0,776 & 0,871 \\
\hline $\begin{array}{l}\text { Calcário calcítico } \\
\text { Limestone }\end{array}$ & 0,667 & 0,715 & 1,143 & 1,276 \\
\hline $\begin{array}{l}\text { Sal comum } \\
\text { Comun salt }\end{array}$ & 0,209 & 0,230 & 0,382 & 0,440 \\
\hline Volumoso & 78,000 & 76,000 & 61,000 & 56,000 \\
\hline $\begin{array}{r}\text { Roughage } \\
\text { Uréia* } \\
\text { Urea* }^{*}\end{array}$ & 0,745 & 0,766 & 0,618 & 0,562 \\
\hline
\end{tabular}

* Somente oferecida aos animais alimentados com cana-deaçúcar.

* Only offered to the animals fed chopped sugar cane.

O abate dos novilhos ocorreu conforme o fluxo normal do matadouro. Após o abate, sangria, remoção do couro e evisceração dos animais, as carcaças foram identificadas, lavadas e resfriadas a $-2{ }^{\circ} \mathrm{C}$ por 24 horas. Decorrido esse tempo, as carcaças foram novamente pesadas e realizou-se a avaliação da conformação e maturidade fisiológica, usando a metodologia sugerida por Müller (1987).

As carcaças foram medidas para obter-se o comprimento de carcaça, de perna e de braço, além do perímetro de braço e espessura de coxão. Logo após foi realizado um corte perpendicular no músculo Longissimus dorsi, na altura da $12^{\mathrm{a}}$ costela, onde foram avaliadas as características cor, textura e marmoreio de carne. Também no mesmo corte foi medida a área de Longissimus dorsi e a espessura de gordura sobre o mesmo.

Para determinar a porcentagem dos cortes comerciais, dividiu-se a meia-carcaça direita em dianteiro, traseiro e costilhar, e por intermédio de pesagem, calculou-se a porcentagem destes em relação à meia-carcaça. A determinação da composição física da carcaça, foi feita por meio dos procedimentos propostos por Hankins \& Howe (1946). A porção do 
músculo Longissimus dorsi, extraída dessa peça, foi embalada, identificada e congelada. Após o congelamento, foram extraídas de cada amostra, duas fatias (fatias A e B) de $2,5 \mathrm{~cm}$, obtidas perpendicularmente ao comprimento do músculo.

As perdas ao descongelamento e cocção, foram calculadas com a pesagem da fatia B congelada, depois de descongelada e após o cozimento, que aconteceu até que a temperatura interna da fatia atingisse $70^{\circ} \mathrm{C}$. A pesagem após o cozimento foi realizada após a fatia voltar à temperatura ambiente. Depois do cozimento e pesagem da fatia, foram extraídas três amostras de feixes de fibras, circulares, com $1 \mathrm{~cm}^{2}$ de área, as quais foram cortadas perpendicularmente à fibra, por meio do aparelho Warner-Bratzler Shear, que mediu a força necessária para cizalhar as fibras musculares.

A fatia A foi descongelada e cozida juntamente com a fatia $\mathrm{B}$, sendo que após a cocção, foram distribuídas, da fatia $\mathrm{A}$, uma porção de $2 \times 2 \mathrm{~cm}$ para cada um dos quatro avaliadores, os quais foram previamente treinados para atribuir valores de 1 a 9 para as características maciez, suculência e palatabilidade da carne, conforme proposto por Müller (1987).

O delineamento experimental foi o inteiramente casualizado, com dois tratamentos e seis repetições. Os dados foram submetidos à análise de variância e teste $\mathrm{F}$ a $5 \%$, por intermédio do programa estatístico SAS (1990). O mesmo programa foi utilizado no estudo de correlação entre as variáveis dependentes por meio do cálculo dos coeficientes de correlação de Pearson.

\section{Resultados e Discussão}

Na Tabela 2 são mostrados os dados referentes às características de peso ao abate, peso de carcaça, rendimento e quebra durante o resfriamento da carcaça, conforme o volumoso oferecido aos novilhos. Os animais que receberam ração à base de silagem de milho apresentaram maior peso de abate que aqueles alimentados com cana-de-açúcar (446 vs $421 \mathrm{~kg} ; \mathrm{P}=0,0227$ ). Alimentando novilhos Charolês em confinamento com silagem de milho ou cana-de-açúcar, Brondani \& Restle (1991) verificaram maior velocidade de crescimento nos primeiros, sendo que esses atingiram o peso de abate de $420 \mathrm{~kg}$, aos 88 dias de confinamento, enquanto que os novilhos que receberam cana-de-açúcar somente atingiram tal peso após 110 dias de confinamento, fato que os pesquisadores atribuíram ao menor teor de proteína e maior teor de fibra desse volumoso.

$\mathrm{O}$ maior peso de abate resultou em maiores $(\mathrm{P}=0,0030)$ pesos de carcaça quente e de carcaça fria $(\mathrm{P}=0,0022)$ nos animais que consumiram silagem de milho (Tabela 2), sendo de 230 e $227 \mathrm{~kg}$, respectivamente, contra 211 e $208 \mathrm{~kg}$, citados na mesma ordem, nos animais alimentados com cana-de-açúcar.

A quebra no resfriamento foi similar entre os tratamentos, sendo de 1,45 e $1,31 \%$, respectivamente, para animais alimentados com cana-de-açúcar e silagem de milho $(\mathrm{P}=0,7903)$. Trabalhando com três sistemas alimentares distintos durante a terminação, Müller et al. (1994) observaram maior quebra ao

Tabela 2 - Médias e erros-padrão (EP) para peso de fazenda, pesos de carcaça quente e fria, quebra no resfriamento e rendimento de carcaça fria de novilhos Hereford alimentados com duas fontes de volumoso

Table 2 - Means and standard errors (EP) for slaughter weight, hot and cold carcass weight, chilling loss and cold dressing percentage of Hereford steers fed two roughage sources

\begin{tabular}{|c|c|c|c|c|}
\hline \multirow[t]{2}{*}{$\begin{array}{l}\text { Característica } \\
\text { Characteristic }\end{array}$} & \multicolumn{2}{|c|}{$\begin{array}{l}\text { Fonte de volumoso } \\
\text { Roughage source }\end{array}$} & \multirow[t]{2}{*}{$\mathrm{EP}$} & \multirow[t]{2}{*}{$\begin{array}{c}\text { Probabilidade } \\
\text { Probability }\end{array}$} \\
\hline & $\begin{array}{c}\text { Cana-de-açúcar } \\
\text { Chopped sugar cane }\end{array}$ & $\begin{array}{l}\text { Silagem de milho } \\
\text { Corn silage }\end{array}$ & & \\
\hline $\begin{array}{l}\text { Peso de fazenda, } \mathrm{kg} \\
\text { Slaughter weight, } \mathrm{kg}\end{array}$ & 421 & 446 & 6,5 & 0,0227 \\
\hline $\begin{array}{l}\text { Peso de carcaça quente, } \mathrm{kg} \\
\text { Hot carcass weight, } \mathrm{kg}\end{array}$ & 211 & 230 & 3,4 & 0,0030 \\
\hline $\begin{array}{l}\text { Peso de carcaça fria, } \mathrm{kg} \\
\text { Cold carcass weight, } \mathrm{kg}\end{array}$ & 208 & 227 & 3,3 & 0,0022 \\
\hline $\begin{array}{l}\text { Quebra no resfriamento, \% } \\
\text { Chilling loss, \% }\end{array}$ & 1,45 & 1,31 & 0,37 & 0,7903 \\
\hline $\begin{array}{l}\text { Rendimento de carcaça fria, } \% \\
\text { Cold dressing percentage, } \%\end{array}$ & 50,1 & 51,5 & 0,61 & 0,1283 \\
\hline
\end{tabular}


resfriamento $(2,87 \%)$ nos animais mantidos em pastagem nativa de baixa qualidade, em relação àqueles mantidos em pastagens cultivadas de melhor qualidade $(2,00 \%)$, fator que os autores relacionaram ao menor acabamento das carcaças dos primeiros.

O rendimento de carcaça não foi afetado pelo tipo de volumoso utilizado na dieta, sendo de 50,1 e 51,5\%, respectivamente, para novilhos alimentados com canade-açúcar e silagem de milho. Estudando novilhos Guzerá confinados com silagem de milheto, cana-deaçúcar, cana-de-açúcar com probiótico, cana-de-açúcar hidrolisada ou silagem de milho, Oliveira et al. (2001) verificaram similaridade no rendimento de carcaça dos animais, sendo de 53,30; 53,28; 53,42; 54,59; e 54,04\%, respectivamente. Di Marco (1998) afirmou que deve ser esperado menor rendimento de carcaça em animais alimentados com volumosos mais fibrosos, mas ressalta também que o nível de concentrado utilizado teria maior influência sobre o rendimento de carcaça, pelo seu efeito direto sobre o conteúdo do trato digestivo no momento da pesagem do animal ainda vivo, sendo que essa diferença tende a desaparecer com o avanço do tempo de jejum.

No presente trabalho, a diferença não significativa $(\mathrm{P}=0,1283)$ de 1,4 ponto percentual no rendimento de carcaça, após 12 horas de jejum, a favor dos animais alimentados com volumoso de melhor qualidade, indica que se os animais fossem pesados sem jejum, poderia ser observado menor rendimento de carcaça nos animais alimentados com cana-de-açúcar. Nos próximos trabalhos, esses pesos podem ser tomados visando gerar resultados aos produtores rurais, os quais realizam a comercialização dos animais em função do peso vivo na propriedade sem jejum, embora essa forma de comercialização ainda exista em poucos estados brasileiros e tenda a ser substituída pela remuneração em relação ao peso de carcaça.

Berg \& Butterfield (1976) afirmaram que outros fatores relacionados ao rendimento de carcaça, em animais contemporâneos, pertencentes ao mesmo rebanho e raça, estariam ligados à deposição de gordura na carcaça. Entretanto, os animais do presente trabalho apresentaram resultados similares de espessura de gordura, composição física, conformação, área de Longissimus dorsi (Tabela 3).

Os animais alimentados com silagem de milho apresentaram 4,91 $\mathrm{mm}$ de espessura de gordura e os animais que consumiram cana-de-açúcar mostraram $5,17 \mathrm{~mm}(\mathrm{P}=0,7071)$, sendo que ao ajustar a cobertura de gordura ao peso de carcaça dos animais, constata-se que o valor continua sendo similar $(\mathrm{P}=0,3186)$ para os dois tratamentos $(2,45$ e $2,15 \mathrm{~mm} /$ $100 \mathrm{~kg}$ de carcaça fria) (Tabela 3 ).

A porcentagem de gordura foi de 20,6 e 23,2\%, respectivamente, para os tratamentos cana-de-açúcar e silagem de milho ( $\mathrm{P}=0,0830)$, ao passo que a porcentagem de músculo na carcaça, foi de 64,2 e 63,3\% $(\mathrm{P}=0,4911)$, citados na mesma ordem (Tabela 3$)$. Gigli et al. (1994) estudaram animais alimentados com rações com dois níveis energéticos e concluíram que o maior nível energético aumentou o total de gordura na carcaça, assim como a gordura intermuscular e subcutânea. Resultados semelhantes aos de Restle et al. (1998b), que observaram diferença significativa no percentual de gordura na carcaça entre novilhos alimentados com silagem de sorgo forrageiro $(18,1 \%) \mathrm{e}$ silagem de sorgo de duplo propósito (20,2\%).

Ao compararem a terminação em confinamento de novilhos alimentados com silagem de milho, de sorgo granífero ou de sorgo forrageiro, Silva et al. (1991) verificaram similaridade somente na porcentagem de ossos da carcaça, pois a porcentagem de músculo decresceu à medida que melhorou a qualidade do volumoso, graças ao aumento na porcentagem de gordura na carcaça $(22,0$ e $17,0 \%$, respectivamente, para silagem de milho e silagem de sorgo forrageiro). Comparando silagem de milho e bagaço de cana-de-açúcar na terminação de tourinhos jovens Santa Gertrudis, Berndt et al. (2002) observaram maior deposição de energia corporal nos primeiros, uma vez que o bagaço de cana propiciou um ambiente ruminal pior para o desempenho do animal que o obtido com uso da silagem de milho.

Não houve diferença $(\mathrm{P}=0,7402)$ na conformação de carcaça dos novilhos dos dois tratamentos, sendo classificada como "regular mais" (9,33 pontos) nos animais alimentados com cana-de-açúcar e "boa menos" ( 9,67 pontos) nos novilhos que consumiram silagem de milho. Müller et al. (1994) verificaram que a conformação de carcaça foi similar entre os animais alimentados em diferentes sistemas de alimentação, sendo a conformação de 9,$0 ; 8,5$ e 8,5 pontos, respectivamente, para bubalinos terminados em pastagem cultivada, animais que pastejaram somente em campo nativo e animais que pastejaram duas horas em pastagem cultivada e o restante do tempo permaneceram em campo nativo.

A área de Longissimus dorsi foi semelhante entre os tratamentos, sendo de 56,4 e $59,7 \mathrm{~cm}^{2}$ para novilhos alimentados com cana-de-açúcar e silagem de milho, respectivamente, sendo que ao ajuste para

R. Bras. Zootec., v.34, n.1, p.230-238, 2005 
Tabela 3 - Médias e erros-padrão (EP) para espessura de gordura de cobertura, composição física da carcaça, conformação e área de Longissimus dorsi da carcaça de novilhos Hereford alimentados com duas fontes de volumoso

Table 3 - Means and standard errors (EP) for subcutaneous fat thickness, carcass physical composition, conformation and longissimus dorsi area of Hereford steers fed two roughage sources

\begin{tabular}{|c|c|c|c|c|}
\hline \multirow[t]{2}{*}{$\begin{array}{l}\text { Característica } \\
\text { Characteristic }\end{array}$} & \multicolumn{2}{|c|}{$\begin{array}{l}\text { Fonte de volumoso } \\
\text { Roughage source }\end{array}$} & \multirow[t]{2}{*}{$\mathrm{EP}$} & \multirow[t]{2}{*}{$\begin{array}{c}\text { Probabilidade } \\
\text { Probability }\end{array}$} \\
\hline & $\begin{array}{l}\text { Cana-de-açúcar } \\
\text { Chopped sugar cane }\end{array}$ & $\begin{array}{l}\text { Silagem de milho } \\
\text { Corn silage }\end{array}$ & & \\
\hline Espessura de gordura, mm & 5,17 & 4,91 & 0,46 & 0,7071 \\
\hline $\begin{array}{l}\text { Fat thickness, } \mathrm{mm} \\
\mathrm{mm} / 100 \mathrm{~kg} \text { de carcaça } \\
\mathrm{mm} / 100 \mathrm{~kg} \text { carcass }\end{array}$ & 2,45 & 2,15 & 0,21 & 0,3186 \\
\hline $\begin{array}{l}\text { Porcentagem de gordura na carcaça } \\
\text { Carcass fat percentage }\end{array}$ & 20,6 & 23,2 & 0,97 & 0,0830 \\
\hline $\begin{array}{l}\text { Porcentagem de osso na carcaça } \\
\text { Carcass bone percentage }\end{array}$ & 16,0 & 14,7 & 0,73 & 0,2486 \\
\hline $\begin{array}{l}\text { Porcentagem de músculo na carcaça } \\
\text { Carcass muscle percentage }\end{array}$ & 64,2 & 63,3 & 0,91 & 0,4911 \\
\hline $\begin{array}{l}\text { Conformação, pontos }{ }^{1} \\
\text { Conformation, points }{ }^{1}\end{array}$ & 9,33 & 9,67 & 0,69 & 0,7402 \\
\hline $\begin{array}{l}\text { Área Longissimus dorsi, } \mathrm{cm}^{2} \\
\text { Longissimus dorsi area, } \mathrm{cm}^{2}\end{array}$ & 56,4 & 59,7 & 2,80 & 0,4340 \\
\hline $\begin{array}{l}\mathrm{cm}^{2} / 100 \mathrm{~kg} \text { de carcaça } \\
\mathrm{cm}^{2} / 100 \mathrm{~kg} \text { carcass }\end{array}$ & 26,8 & 26,1 & 1,34 & 0,7153 \\
\hline
\end{tabular}

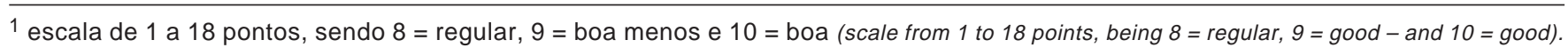

o peso de carcaça resultou em valores de 26,8 e $26,1 \mathrm{~cm}^{2} / 100 \mathrm{~kg}$ de carcaça, citados na mesma ordem (Tabela 3). Silva et al. (1991) verificaram similaridade na área de Longissimus dorsi de novilhos alimentados com dois tipos de silagem. Comparando silagem de milho e cana-de-açúcar na dieta de novilhos bubalinos, Vaz et al. (2003) verificaram similaridade nessas características, observando valores de $52,4 \mathrm{~cm}^{2}$ e $28,7 \mathrm{~cm}^{2} / 100 \mathrm{~kg}$ de carcaça, para animais alimentados com cana e $51,7 \mathrm{~cm}^{2}$ e $27,6 \mathrm{~cm}^{2} / 100 \mathrm{~kg}$ de carcaça para os animais alimentados com silagem. Berg \& Butterfield (1976) comentam que, em animais contemporâneos da mesma raça, não são esperadas diferenças significativas na área de Longissimus dorsi ajustada para o peso de carcaça dos animais.

$\mathrm{Na}$ Tabela 4, são apresentados os resultados referentes às porcentagens dos cortes da carcaça. Os animais alimentados com silagem de milho apresentaram 36,8; 14,2 e 49,0\%, respectivamente, para as percentagens de dianteiro, de costilhar e de serrote, enquanto nos animais alimentados com cana-de-açúcar esses valores foram de 36,6; 13,7 e 49,7\%, sendo que nenhuma destas três características diferiu $(\mathrm{P}>0,05)$ entre os tratamentos.

Estudando o uso de silagem de milho ou de sorgo forrageiro, Silva et al. (1991) observaram menor percentagem de serrote nos primeiros, verificando similaridade entre os tratamentos nas percentagens de costilhar e de dianteiro.

Observando-se os resultados referentes às medidas de desenvolvimento da carcaça, verifica-se que a espessura de coxão, o comprimento de perna e de braço foram similares entre os tratamentos, mas os animais alimentados com silagem de milho apresentaram maior comprimento de carcaça $(125,0 \mathrm{~cm} ; \mathrm{P}=0,0198)$ e perímetro de braço $(36,0 \mathrm{~cm}$; $\mathrm{P}=0,0193)$ do que naqueles que consumiram canade-açúcar (122,0 e 34,1 cm). Comparando silagens de duas variedades de sorgo, Restle et al. (1998a) não verificaram diferença no comprimento de carcaça e de perna dos novilhos. Silva et al. (1991) verificaram que a fonte de volumoso não alterou as medidas comprimento de carcaça e espessura de coxão.

As médias para as características cor, textura e marmoreio da carne são apresentadas na Tabela 5. Observa-se que os dois grupos de novilhos apresentaram carne com coloração vermelho brilhante e a mesma média numérica (4,67 pontos).

Restle et al. (1998b) relatam valores de 3,61 e 3,60 pontos para coloração da carne de animais alimentados com silagem de sorgo forrageiro ou de sorgo duplo propósito, respectivamente. Para Pardi et al. (1993), as variações na coloração da carne são decorrentes de problemas com estresse pré-abate, ou 
Tabela 4 - Médias e erros-padrão (EP) para percentagem dos cortes comerciais e medidas de desenvolvimento da carcaça de novilhos Hereford alimentados com duas fontes de volumoso

Table 4 - Means and standard error (EP) for commercial cuts percentages and carcass development measures of Hereford steers fed two roughage sources

\begin{tabular}{|c|c|c|c|c|}
\hline \multirow[t]{2}{*}{$\begin{array}{l}\text { Característica } \\
\text { Characteristic }\end{array}$} & \multicolumn{2}{|c|}{$\begin{array}{l}\text { Fonte de volumoso } \\
\text { Roughage source }\end{array}$} & \multirow[t]{2}{*}{$\mathrm{EP}$} & \multirow[t]{2}{*}{$\begin{array}{c}\text { Probabilidade } \\
\text { Probability }\end{array}$} \\
\hline & $\begin{array}{c}\text { Cana-de-açúcar } \\
\text { Chopped sugar cane }\end{array}$ & $\begin{array}{l}\text { Silagem de milho } \\
\text { Corn silage }\end{array}$ & & \\
\hline $\begin{array}{l}\text { Porcentagem de dianteiro } \\
\text { Forequarter percentage }\end{array}$ & 36,6 & 36,8 & 0,35 & 0,8434 \\
\hline $\begin{array}{l}\text { Porcentagem de costilhar } \\
\text { Sidecutpercentage }\end{array}$ & 13,7 & 14,2 & 0,40 & 0,3898 \\
\hline $\begin{array}{l}\text { Porcentagem de serrote } \\
\text { Sawcutpercentage }\end{array}$ & 49,7 & 49,0 & 0,31 & 0,1409 \\
\hline $\begin{array}{l}\text { Comprimento de carcaça, cm } \\
\text { Carcass length, } \mathrm{cm}\end{array}$ & 122 & 125 & 0,96 & 0,0198 \\
\hline $\begin{array}{l}\text { Comprimento de perna, } \mathrm{cm} \\
\text { Leg length, } \mathrm{cm}\end{array}$ & 63,5 & 63,8 & 0,89 & 0,7961 \\
\hline $\begin{array}{l}\text { Espessura de coxão, cm } \\
\text { Cushion thickness, } \mathrm{cm}\end{array}$ & 22,0 & 22,8 & 0,81 & 0,4861 \\
\hline $\begin{array}{l}\text { Perímetro de braço, } \mathrm{cm} \\
\text { Arm perimeter, } \mathrm{cm}\end{array}$ & 34,1 & 36,0 & 0,49 & 0,0193 \\
\hline $\begin{array}{l}\text { Comprimento de braço, } \mathrm{cm} \\
\text { Arm length, } \mathrm{cm}\end{array}$ & 37,8 & 38,0 & 0,35 & 0,6250 \\
\hline
\end{tabular}

em função de diferenças na condição sexual ou maturidade fisiológica entre animais contemporâneos, mas pouco efeito direto deve ser esperado com a alteração da qualidade da dieta.

A textura e o marmoreio da carne também foram similares entre os dois grupos de novilhos, embora estas características tenham sido classificadas como "fina" e "leve mais", respectivamente, nos animais terminados com cana-de-açúcar, e como "muito fina" e "pequeno menos", na mesma ordem, no tratamento com silagem de milho. Vaz et al. (2003) verificaram textura classificada entre "média" e"fina", e marmoreio "leve menos" para búfalos alimentados com cana-deaçúcar e textura "fina" e marmoreio "traços mais" nos búfalos tratados com silagem de milho.

Os resultados de força de cizalhamento necessária para romper as fibras da carne dos novilhos dos dois tratamentos foram bastante similares, com média de 7,22 kg (Tabela 5). As variáveis maciez, palatabilidade e suculência também foram similares ( $P>0,05)$ entre os tratamentos, sendo de 5,58; 5,54 e 5,04 pontos, respectivamente, no tratamento canade-açúcar e 5,88; 6,08 e 5,42 pontos, citados na mesma ordem no tratamento silagem de milho. Restle et al. (1998a) concluíram que o volumoso utilizado durante a terminação de novilhos não altera as características sensoriais da carne. Lawrie (1970) não espera alterações nas características sensoriais da carne, quando não existe alteração no grau de acabamento, peso ou idade ao abate, mas Vaz et al. (2003) terminaram bubalinos em confinamento aos 20 meses, verificando carne de melhor palatabilidade e maior suculência nos animais terminados com cana-de-açúcar, em relação aos que receberam silagem de milho.

A quebra durante o descongelamento foi maior $(\mathrm{P}=0,0367)$ nos animais tratados com cana-de-açúcar $(6,10 \%)$ que nos animais tratados com silagem de milho $(3,69 \%)$, mas a quebra durante a cocção foi similar entre os dois grupos de novilhos $(\mathrm{P}=0,5145)$. Restle et al. (1998b) compararam dois volumosos na alimentação de novilhos, observando valores similares nas quebras ao descongelamento e à cocção da carne, entre os tratamentos. Por outro lado, Vaz et al. (2003) observaram diferença na quebra durante o descongelamento da carne, que foi menor nos animais alimentados com silagem de milho $(4,80 \%)$ em relação aos alimentados com cana-de-açúcar $(5,83 \%)$.

Consta da Tabela 6 as correlações entre as variáveis analisadas. Verifica-se que a correlação foi significativa entre rendimento e peso de carcaça ( $\mathrm{r}=0,58 ; \mathrm{P}<0,05)$, uma vez que, segundo Di Marco (1994), em bovinos, o rendimento de carcaça aumenta com o incremento no peso de abate, em função do maior grau de acabamento dos animais com maior peso de carcaça. Entretanto, neste estudo, os coeficientes de correlação entre rendimento de carcaça e espessura de 
Tabela 5 - Médias e erros-padrão (EP) para cor, textura, marmoreio, força de cizalhamento, características sensoriais e quebras durante o descongelamento e cocção da carne de novilhos Hereford alimentados com duas fontes de volumoso

Table 5 - Means and standard errors (EP) for meat color, texture, marbling, Shear force, sensorial characteristics, thawing and cooking losses of Hereford steers fed two roughage sources

\begin{tabular}{|c|c|c|c|c|}
\hline \multirow[t]{2}{*}{$\begin{array}{l}\text { Característica } \\
\text { Characteristic }\end{array}$} & \multicolumn{2}{|c|}{$\begin{array}{l}\text { Fonte de volumoso } \\
\text { Roughage source }\end{array}$} & \multirow[t]{2}{*}{$\mathrm{EP}$} & \multirow[t]{2}{*}{$\begin{array}{l}\text { Probabilidade } \\
\text { Probability }\end{array}$} \\
\hline & $\begin{array}{l}\text { Cana-de-açúcar } \\
\text { Chopped sugar cane }\end{array}$ & $\begin{array}{l}\text { Silagem de milho } \\
\text { Corn silage }\end{array}$ & & \\
\hline $\begin{array}{l}\text { Cor, pontos }{ }^{1} \\
\text { Meat color, points }{ }^{1}\end{array}$ & 4,67 & 4,67 & 0,21 & 1,0000 \\
\hline $\begin{array}{l}\text { Textura, pontos }{ }^{2} \\
\text { Meat texture, points }{ }^{2}\end{array}$ & 4,33 & 4,67 & 0,21 & 0,2897 \\
\hline $\begin{array}{l}\text { Marmoreio, pontos } \\
\text { Marbling, points }^{3}\end{array}$ & 6,17 & 7,33 & 1,05 & 0,4503 \\
\hline $\begin{array}{l}\text { Força de cizalhamento, } \mathrm{kg} \\
\text { Shear force, } \mathrm{kg}\end{array}$ & 7,21 & 7,23 & 0,58 & 0,9779 \\
\hline $\begin{array}{l}\text { Maciez, pontos }{ }^{4} \\
\text { Tenderness, points } 4\end{array}$ & 5,58 & 5,88 & 0,41 & 0,6274 \\
\hline $\begin{array}{l}\text { Palatabilidade, pontos }{ }^{4} \\
\text { Flavor, points }{ }^{4}\end{array}$ & 5,54 & 6,08 & 0,22 & 0,1181 \\
\hline $\begin{array}{l}\text { Suculência, pontos }{ }^{4} \\
\text { Juiciness, points }{ }^{4}\end{array}$ & 5,04 & 5,42 & 0,24 & 0,2987 \\
\hline $\begin{array}{l}\text { Quebra no descongelamento, \% } \\
\text { Thawing loss, \% }\end{array}$ & 6,10 & 3,69 & 0,71 & 0,0367 \\
\hline $\begin{array}{l}\text { Quebra na cocção, \% } \\
\text { Cooking loss, \% }\end{array}$ & 33,5 & 32,4 & 1,14 & 0,5145 \\
\hline
\end{tabular}

${ }^{1}$ Escala de 1 a 5 pontos, sendo $1=$ vermelho escuro e 5 = vermelho brilhante.

1 Scale from 1 to 5 points, being $1=$ dark red and $5=$ bright red.

2 Escala de 1 a 5 pontos, sendo $1=$ muito grosseira e $5=$ muito fina.

2 Scale from 1 to 5 points, being $1=$ very coarse and $5=$ very fine.

${ }^{3}$ Escala de 1 a 18 pontos, sendo $6=$ leve mais, $7=$ pequeno menos e $8=$ pequeno.

${ }^{3}$ Scale from 1 to 18 points, being $6=$ slight plus, $7=$ small minus and $8=$ small.

4 Escala de 1 a 9 pontos, sendo 1 = extremamente dura, sem sabor ou seca, 5 = médio e 9 = extremamente macia, extremamente saborosa ou extremamente suculenta.

${ }^{4}$ Scale from 1 to 9 points, being 1 = extremly tough, undesirable flavor or dry, $5=$ average and $9=$ extremly tender, flavorful or juicy.

gordura e rendimento de carcaça e porcentagem de gordura estiveram próximos de zero $(\mathrm{P}>0,10)$.

A quebra ao resfriamento da carcaça (Tabela 6) esteve positivamente correlacionada com o percentual de serrote $(\mathrm{r}=0,70 ; \mathrm{P}<0,01)$ e negativamente correlacionada com a conformação de carcaça $(\mathrm{r}=-0,54 ; \mathrm{P}<0,10)$. Ao observarem correlação alta e negativa entre quebra ao resfriamento e conformação, Vaz et al. (2003) concluíram que carcaças mais compridas e com maior musculosidade apresentaram menores perdas durante o resfriamento.

A correlação entre porcentagem de costilhar e as características que expressam a deposição de gordura na carcaça também foi alta, o que se justifica, de acordo com Vaz (1999), pelo de fato de que, após determinado grau de acabamento, a deposição de gordura se acentua no corte costilhar, aumentando o percentual deste corte em relação aos demais.

$\mathrm{O}$ teor de gordura na carcaça também esteve significativamente correlacionado com a maciez da

R. Bras. Zootec., v.34, n.1, p.230-238, 2005 carne $(r=0,59 ; \mathrm{P}<0,05)$. A deposição de gordura inter e intramuscular aumentam a maciez e melhoram a palatabilidade da carne, pois o desprendimento de gordura durante a mastigação facilita a fragmentação dos feixes de fibras musculares, além de melhorar a lubrificação do bolo alimentar (Preston \& Willis, 1974; Berg \& Butterfield, 1976; Vaz \& Restle, 2000). No presente trabalho, a correlação entre palatabilidade da carne e percentual de gordura ou marmoreio da carne não foram significativos $(\mathrm{P}>0,10)$.

Vaz \& Restle (2000) relataram que não existiu correlação entre as variáveis marmoreio e palatabilidade da carne de novilhos castrados. No presente trabalho, foi observada correlação alta e negativa entre palatabilidade da carne e quebra ao descongelamento $(\mathrm{r}=-0,59 ; \mathrm{P}<0,05)$. As perdas durante o descongelamento e a cocção estiveram também correlacionadas com a suculência da carne $(\mathrm{P}<0,05)$, comprovando sua redução na quantidade de líquidos retidos na carne. 


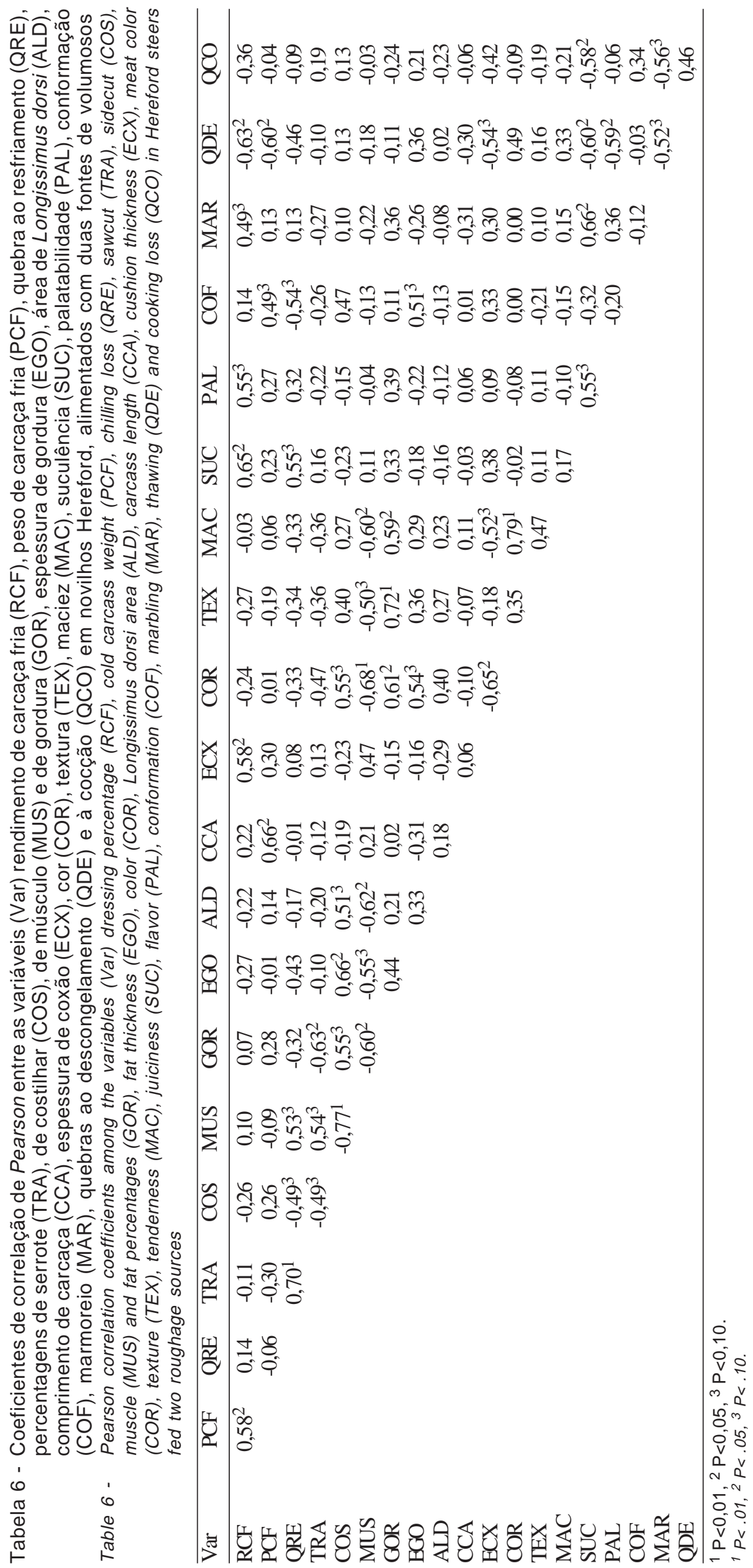




\section{Conclusões}

Novilhos Hereford terminados em confinamento com silagem de milho apresentam maior peso de abate e pesos de carcaças quente e fria, carcaça mais comprida, com maior perímetro de braço e maior percentual de gordura que os animais alimentados com cana-de-açúcar, sob as mesmas condições.

Não houve diferença entre novilhos terminados com cana-de-açúcar ou silagem de milho no rendimento dos cortes comerciais e nas características qualitativas da carne e da carcaça.

A correlação entre maciez da carne e medidas que expressam a deposição de gordura na carcaça, como espessura de gordura e percentual de gordura na carcaça foi alta e positiva.

\section{Literatura Citada}

BERG, R.T.; BUTTERFIELD, R.M. New concepts of cattle growth. Sydney: Sydney University Press, 1976. 240p.

BERNDT, A.; HENRIQUE, W.; LANNA, D.P.D. Milho úmido, bagaço de cana e silagem de milho em dietas de alto teor de concentrado. Composição corporal e taxas de deposição dos tecidos. Revista Brasileira de Zootecnia, v.31, n.5, p.2105-2112, 2002.

BRONDANI, I.L.; RESTLE, J. Efeito das dietas contendo canade-açúcar ou silagem de milho no desempenho de novilhos em confinamento. Ciência Rural, v.21, n.1, p.129-134, 1991.

DI MARCO, O.N. Crecimiento y respuesta animal. Balcarce: Associación Argentina de Producción Animal, 1994. 129p.

DI MARCO, O.N. Crecimiento de vacunos para carne. Mar Del Plata: Oscar N. Di Marco, 1998. 246p.

GIGLI, S.; FAILLA, S.; CARRETTA, A. et al. Growth of young bulls: live weight, carcass and meat. In: WORLD BUFFALO CONGRESS, 4., 1994, São Paulo. Proceedings... São Paulo: Associação Brasileira de Criadores de Búfalos/FAO/FINEP, 1994, v.2, p.18-20.

HANKINS, O.G.; HOWE, P.E. Estimation of the composition of beef carcasses and cuts. Washington: United States Department of Agriculture, 1946. 20p. (Technical Bulletin, 926)

LAWRIE, R.A. Ciência de la carne. Zaragoza: Acribia, 1970. 342p.

MULLER, L. Normas para avaliação de carcaças e concurso de carcaça de novilhos. 2.ed. Santa Maria: Universidade Federal de Santa Maria, 1987. 31p.

MULLER, L.; AGUIRRE, L.F.; FEIJÓ, G.L.D. et al. Buffalo meat quality when submitted to three feeding regimens. In: WORLD BUFFALO CONGRESS, 4., 1994, São Paulo, Proceedings... São Paulo: Associação Brasileira de Criadores de Búfalos/FAO/FINEP, 1994, v.2, p.107-109.

OLIVEIRA, B.S.Y.; ALVES, J.B.; BERGAMASCHINE, A.F. Desempenho de bovinos terminados em confinamento, com diferentes volumosos. In: REUNIÃO ANUAL DA SOCIEDADE BRASILEIRA DEZOOTECNIA, 38.,Piracicaba, 2001.Anais... Piracicaba: Sociedade Brasileira deZootecnia, 2001.(CD-ROM)

PARDI, M.C.; SANTOS, I.F.; SOUZA, E.R. et al. Ciência, higiene e tecnologia da carne. Goiânia: Universidade Federal de Goiás, 1993.

PRESTON, T.R.; WILLIS, M.B. Intensive beef production. 2.ed. Oxford: Pergamon Press, 1974. 546p.
RESTLE, J.; BRONDANI, I.L.; ESCOBAR, R.B. et al. Efeito de dietas contendo farelo de arroz integral ou desengordurado, combinado com silagem de milho ou de sorgo forrageiro no desempenho de novilhos. In: REUNIÃO ANUAL DA SOCIEDADE BRASILEIRA DE ZOOTECNIA, 33., Fortaleza, 1996. Anais... Fortaleza: SBZ, 1996, p.108-110.

RESTLE, J.; SILVA, N.L.Q.; VAZ, F.N. et al. Aspectos quantitativos da carcaça de novilhos terminados aos 24 meses com diferentes silagens de sorgo. In: REUNIÃO ANUAL DA SOCIEDADE BRASILEIRA DE ZOOTECNIA, 35., Botucatu, 1998. Anais... Botucatu: Sociedade Brasileira de Zootecnia, 1998a, p.137-139.

RESTLE, J.; VAZ, F.N.; QUADROS, A.R.B. et al. Características de carcaça e da carne de novilhos de diferentes genótipos de Hereford $x$ Nelore. Revista Brasileira de Zootecnia, v.28, n.6, p.1245-1251, 1999.

RESTLE, J.; VAZ, F.N.; SILVA, N.L.Q. et al. Aspectos qualitativos da carcaça e da carne de novilhos terminados aos 24 meses com diferentes silagens de sorgo. In: REUNIÃO ANUAL DA SOCIEDADE BRASILEIRA DE ZOOTECNIA, 35., Botucatu, 1998. Anais... Botucatu: Sociedade Brasileira de Zootecnia, 1998b, p.143-145.

RESTLE, J.; VAZ, F.N. Tendências de mercado e entraves tecnológicos para a cadeia produtiva da carne bovina. In: MELLO, N.A.; ASSMAN, T.S. Encontro de integração lavoura-pecuária no Sul do Brasil, 1., 2002. Pato Branco: IAPAR/CEFET, 2002, p.167-188.

STATISTICAL ANALYSES SYTEM - SAS. SAS language reference. Version 6, Cary: 1990. 1042p.

SHERBECK, J.A.; TATUM, J.D.; FIELD, T.G. et al. Feedlot performance, carcass traits, and palatability traits of Hereford Brahman steers. Journal of Animal Science, v.73, n.12, p.3613-3620, 1995.

SILVA, L.C.R.; RESTLE, J.; MÜLLER, L. Características da carcaça e da carne de novilhos terminados em confinamento com diferentes tipos de silagem. In: REUNIÃO ANUAL DA SOCIEDADE BRASILEIRA DE ZOOTECNIA, 28., 1991, João Pessoa. Anais... João Pessoa: Sociedade Brasileira de Zootecnia, 1991, p.245.

VAZ, F.N. Cruzamento alternado das raças Charolês e Nelore: características de carcaça e da carne de novilhos abatidos aos dois anos. Santa Maria: Universidade Federal de Santa Maria, 1999. 58p. Dissertação (Mestrado em Zootecnia) - Universidade Federal de Santa Maria, 1999.

VAZ, F.N.; RESTLE, J. Produção de carne com qualidade. In: RESTLE, J.; BRONDANI, I.L.; PASCOAL, L.L. et al. (Eds.) Produção intensiva com qualidade em bovinos de corte, Santa Maria: Universidade Federal de Santa Maria, 1998. p.104-119.

VAZ, F.N.; RESTLE, J. Aspectos qualitativos da carcaça e da carne de machos Hereford, inteiros ou castrados, abatidos aos quatorze meses. Revista Brasileira de Zootecnia, v.29, n.6, p.1894-1901, 2000.

VAZ, F.N.; RESTLE, J.; BRONDANI, I.L. et al. Estudo da carcaça e da carne de bubalinos Mediterrâneo terminados em confinamento com diferentes fontes de volumoso. Revista Brasileira de Zootecnia, v.32, n.2, p.393-404, 2003.

VAZ, F.N.; RESTLE, J.; ALVES FILHO, D.C. et al. Peso das vísceras e rendimento de carcaças de novilhos ou novilhas Braford superprecoces, terminados com suplementação em pastagem cultivada sob pastejo controlado. In: REUNIÃO ANUAL DA SOCIEDADE BRASILEIRA DEZOOTECNIA, 38., 2001, Piracicaba, Anais... Viçosa: Sociedade Brasileira de Zootecnia, 2001, p.1531-1532.

Recebido em: 03/11/03 Aceito em: 12/08/04

R. Bras. Zootec., v.34, n.1, p.230-238, 2005 